NASA/TM-2002-211788

IECEC-2002-20075

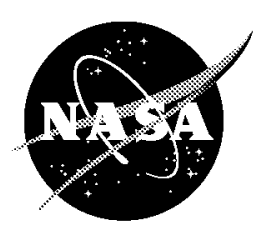

\title{
Redesign of Glenn Research Center D1 Flywheel Module
}

Ralph H. Jansen, Robert C. Wagner, and Kirsten P. Duffy

University of Toledo, Toledo, Ohio

David S. Hervol and Ronald J. Storozuk

Analex Corporation, Brook Park, Ohio

Timothy P. Dever

QSS Group, Inc., Cleveland, Ohio

Salvatore M. Anzalone

Science Applications International Corporation, Cleveland, Ohio

Jeffrey J. Trudell and Kevin E. Konno

Glenn Research Center, Cleveland, Ohio

Andrew Kenny

Texas A\&M University, College Station, Texas 
The NASA STI Program Office ... in Profile

Since its founding, NASA has been dedicated to the advancement of aeronautics and space science. The NASA Scientific and Technical Information (STI) Program Office plays a key part in helping NASA maintain this important role.

The NASA STI Program Office is operated by Langley Research Center, the Lead Center for NASA's scientific and technical information. The NASA STI Program Office provides access to the NASA STI Database, the largest collection of aeronautical and space science STI in the world. The Program Office is also NASA's institutional mechanism for disseminating the results of its research and development activities. These results are published by NASA in the NASA STI Report Series, which includes the following report types:

- TECHNICAL PUBLICATION. Reports of completed research or a major significant phase of research that present the results of NASA programs and include extensive data or theoretical analysis. Includes compilations of significant scientific and technical data and information deemed to be of continuing reference value. NASA's counterpart of peerreviewed formal professional papers but has less stringent limitations on manuscript length and extent of graphic presentations.

- TECHNICAL MEMORANDUM. Scientific and technical findings that are preliminary or of specialized interest, e.g., quick release reports, working papers, and bibliographies that contain minimal annotation. Does not contain extensive analysis.

- CONTRACTOR REPORT. Scientific and technical findings by NASA-sponsored contractors and grantees.
- CONFERENCE PUBLICATION. Collected papers from scientific and technical conferences, symposia, seminars, or other meetings sponsored or cosponsored by NASA.

- SPECIAL PUBLICATION. Scientific, technical, or historical information from NASA programs, projects, and missions, often concerned with subjects having substantial public interest.

- TECHNICAL TRANSLATION. Englishlanguage translations of foreign scientific and technical material pertinent to NASA's mission.

Specialized services that complement the STI Program Office's diverse offerings include creating custom thesauri, building customized data bases, organizing and publishing research results ... even providing videos.

For more information about the NASA STI Program Office, see the following:

- Access the NASA STI Program Home Page at http://www.sti.nasa.gov

- E-mail your question via the Internet to help@sti.nasa.gov

- Fax your question to the NASA Access Help Desk at 301-621-0134

- Telephone the NASA Access Help Desk at 301-621-0390

- Write to: NASA Access Help Desk NASA Center for AeroSpace Information 7121 Standard Drive Hanover, MD 21076 
NASA/TM-2002-211788

IECEC-2002-20075

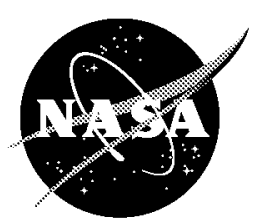

\section{Redesign of Glenn Research Center D1 Flywheel Module}

Ralph H. Jansen, Robert C. Wagner, and Kirsten P. Duffy

University of Toledo, Toledo, Ohio

David S. Hervol and Ronald J. Storozuk

Analex Corporation, Brook Park, Ohio

Timothy P. Dever

QSS Group, Inc., Cleveland, Ohio

Salvatore M. Anzalone

Science Applications International Corporation, Cleveland, Ohio

Jeffrey J. Trudell and Kevin E. Konno

Glenn Research Center, Cleveland, Ohio

Andrew Kenny

Texas A\&M University, College Station, Texas

Prepared for the

37th Intersociety Energy Conversion Engineering Conference

sponsored by the Institute of Electrical and Electronics Engineers, Electron Devices Society

Washington, DC, July 28-August 2, 2002

National Aeronautics and

Space Administration

Glenn Research Center 
Available from

NASA Center for Aerospace Information 7121 Standard Drive

Hanover, MD 21076
National Technical Information Service 5285 Port Royal Road Springfield, VA 22100

Available electronically at http://gltrs.gronasa.goy 


\section{REDESIGN OF GLENN RESEARCH CENTER D1 FLYWHEEL MODULE}

\author{
Ralph H. Jansen \\ Robert C. Wagner \\ Dr. Kirsten Duffy \\ University of Toledo \\ Toledo, Ohio 43606
}

\author{
Salvatore M. Anzalone \\ Science Applications International \\ Corporation \\ Cleveland, Ohio 44135
}

\author{
Timothy P. Dever \\ QSS Group, Inc. \\ Cleveland, Ohio 44135
}

\author{
Jeffrey J. Trudell \\ Kevin E. Konno \\ National Aeronautics and Space Administration \\ Glenn Research Center \\ Cleveland, Ohio 44135
}

\author{
Ronald J. Storozuk \\ Analex Corporation \\ Brook Park, Ohio 44142
}

Andrew Kenny

Texas A\&M University

College Station, Texas 77843

\begin{abstract}
Glenn Research Center has completed the redesign of the D1 flywheel module. The redesign includes a new rotor with a composite rim, motor/generator, touchdown bearings, sensors, and a magnetic actuator. The purpose of the relatively low cost module upgrade is to enable it to continuously operate throughout its speed range of $0-60,000$ RPM. The module will be used as part of a combined attitude control and bus regulation experiment.
\end{abstract}

\section{INTRODUCTION}

NASA Glenn Research Center (GRC) has an ongoing effort in flywheel technology development and deployment. Flywheels are being evaluated for energy storage applications as well as combined systems for energy storage and attitude control. NASA and the USAF have a collaborative program consisting of government, industry, and academic partners working to advance the state of the art in aerospace flywheel systems and migrate the technology to the end users. NASA GRC funds its flywheel technology development through the Aerospace Flywheel Technology Program (AFTP). McLallin (2001) provides an overview of the interrelation of the programs.

One of the AFTP program components being conducted at GRC is the Attitude Control and Energy Storage Experiment (ACESE). The first phase of this program is a demonstration of a two flywheel system which provides DC bus regulation and attitude control capability. Two technology demonstrator flywheel modules that were built under a previous task will be used in this phase.

Both of the flywheel modules required substantial upgrades to provide sufficient performance levels for incorporation into a multiple flywheel demonstration. This paper describes the upgrade of one of those modules. The unit was delivered by a contractor and, after the upgrade, will be referred to as the D1 flywheel module.
This paper describes a design methodology. Requirements derived using that methodology are used to generate a final design. Analytical models are used to verify that the design meets the requirements and results of the analyses are presented.

\section{DESIGN METHODOGY}

\section{Overview}

The D1 Flywheel Module redesign addressed programmatic and technical goals. The programmatic goal was to establish and capture a design process and identify areas where that process could be improved. The technical goal was to build a module that was suitable for continuous reliable operation for a minimum period of 12 hours through the entire operating speed range.

The D1 flywheel module is a magnetically suspended energy storage rotor with a vacuum housing (Figure 1). The rotor consists of a carbon composite rim with a metallic hub. It is suspended by magnetic bearings. A motor/generator is used to transfer energy to and from the rotor. Mechanical touchdown bearings are used to capture the rotor in

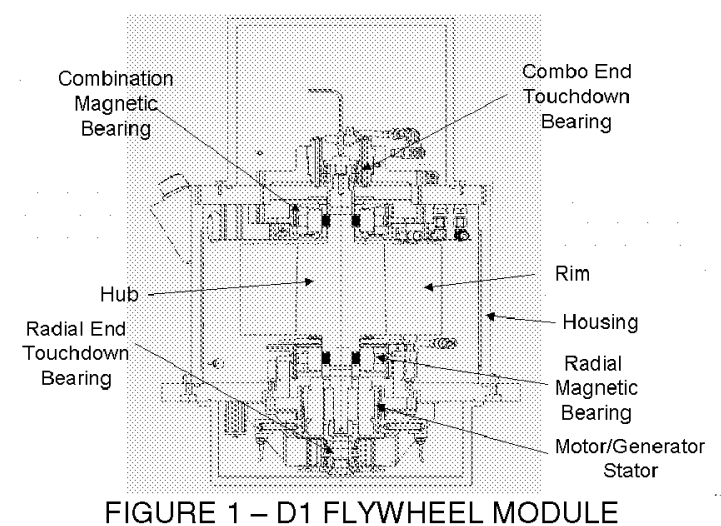

FIGURE 1 - D1 FLYWHEEL MODULE 
case of magnetic bearing failure. They are not engaged during normal operation. The housing structure acts as a vacuum enclosure and provides mechanical support to the other components in the system. The flywheel module is used in conjunction with an avionics package of electronics and control software which operates the magnetic bearing and motor/generator.

As the design process was developed it was captured using a system modeling tool. The intention was to capture lessons learned during the upgrade, develop an approach for streamlining the engineering process, and establish requirements for an integrated design environment to be used on subsequent projects. The main components of the system model are a process model and a system architecture.

\section{Design Process Model}

The process model was used to capture the design processes and how they related to each other. The data inputs and outputs required for each step and tools used in each step were captured in the process model database. A system engineering tool was used to generate functional flow diagrams. The rotor design process (Figure 2) is a typical example. The design functions are captured along with the criteria for completion. The design process can also be viewed in a hierarchical form.

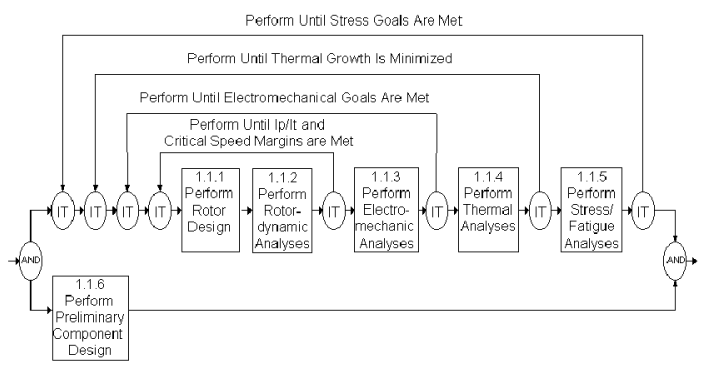

FIGURE 2 - ROTOR DESIGN PROCESS

\section{Flywheel Module Architecture}

A flywheel module architecture was laid out which divided the module into rotating and stationary components. The rotor and stator were further subdivided into components related to the motor/generator, touchdown bearings, magnetic bearings, and housing. Each component continued to be subdivided to whatever level was useful. For example, the magnetic bearing system was divided into the actuator, sensors, and housing. The sensors

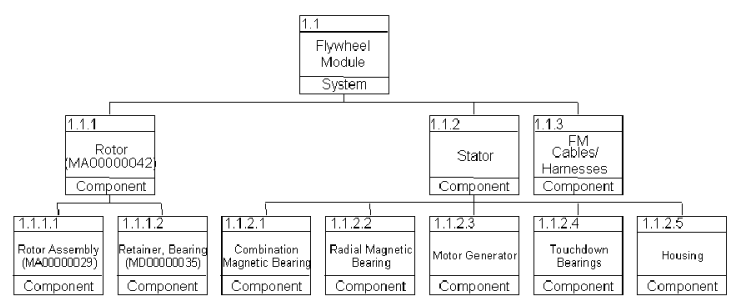

FIGURE 3 - SYSTEM ARCHITECTURE were further divided into the signal conditioner, cables, and sensor head. The highest level system architecture diagram is shown in Figure 3.

\section{REQUIREMENTS}

The first step in the design process was to establish a set of requirements. They could be grouped into reutilization, performance, rotor and avionics requirements. For cost efficiency, the flywheel housing, one touchdown bearing, the cable harnesses, and the magnetic bearing stators were reutilized. The system performance criteria were: minimum of $300 \mathrm{w}$-hr usable energy, a $3 \mathrm{~kW}$ charge/discharge power rating, and a maximum operating speed of 60,000 RPM. The rotor was to have a first bending mode $>110 \%$ of maximum operating speed, the ratio between polar moment of inertia and transverse moment of inertia $(\mathrm{lp} / \mathrm{lt})<0.8$ or $>1.2$, and an operating temperature range between $70-170^{\circ} \mathrm{F}$. The avionics requirement was to simplify the position and tachometer sensor system in the flywheel module to reduce the signal conditioning and control complexity of the avionics.

A verification matrix was established to show how the analysis and tests on the D1 flywheel module related to the requirements. In the matrix each design choice was related back to a requirement and the verification method was listed. The verification method shows how the design choice fulfills the requirement. Three verification methods were available: inspection, analysis, and test. During the design phase only the analysis verification method is available. After the hardware is manufactured it will be inspected or tested as defined by the verification plan.

\section{ROTOR DESIGN}

The rotor components include the rim, hub, motor/generator rotor, and a number of small target pieces for the magnetic bearing actuator, position sensors, and touchdown bearings. The rotor is shown in Figure 4.

The rotor design meets the requirements above except for the temperature range. The rotor energy is $364 \mathrm{~W}$-hr at the maximum normal operating speed of 60,000 RPM. With $90 \%$ depth of discharge there is $328 \mathrm{~W}$-hr of useable energy. The rotor meets all

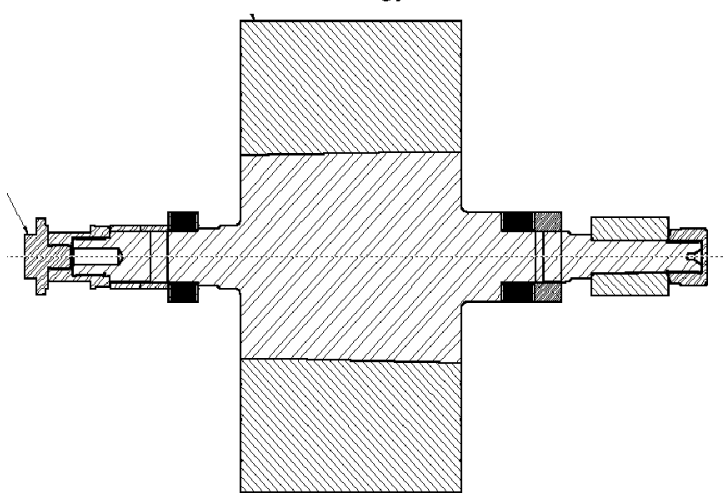

FIGURE 4 - ROTOR DESIGN 
safety margins at the certification speed of 66,000 RPM. It has a first bending mode $117 \%$ of operating speed and an $\mathrm{Ip} / \mathrm{It}$ ratio of 0.80 . The motor power rating is $3 \mathrm{~kW}$. Due to rim material constraints, the upper rotor temperature limit was reduced from $170^{\circ} \mathrm{F}$ to $150^{\circ} \mathrm{F}$. The minimum operating temperature is $70^{\circ} \mathrm{F}$.

\section{$\underline{\text { Rim }}$}

The rim is the main energy storage component. A multiring carbon fiber design was purchased from a commercial source. The risk, cost, and development time were the driving factors in this choice. The rim mounts directly onto the hub with an interference fit. There are no hub geometry changes under the rotor that would induce unnecessary stress concentrations in the rim.

The rim met all requirements except the temperature ratings. The composite rim temperature limit is $150^{\circ} \mathrm{F}$, chosen by derating the $170^{\circ} \mathrm{F}$ glass transition temperature $\left(\mathrm{T}_{\mathrm{g}}\right)$ of the epoxy by $20^{\circ} \mathrm{F}$.

\section{$\underline{\text { Hub }}$}

All of the rotor components are mounted on a central monolithic steel hub. A monolithic hub was chosen for simplicity. Alternative designs with multiple hub parts require verification of joints. The disadvantage of this decision was that it required the redesign of the rotor parts of one of the magnetic bearings.

Material selection was driven by strength, density, and magnetic properties. The minimum needed strength was approximately $100 \mathrm{ksi}$ yield and was driven by rotational, thermal, and assembly stresses. Density affected the $\mathrm{lp} / \mathrm{lt}$ ratio. This ratio needed to be $<0.8$ or $>1.2$ to simplify magnetic bearing control. A non-magnetic hub was required in order for both magnetic bearings and the motor/generator to function as originally designed. The material selected based on these constraints was A286 stainless steel. Other desirable properties were corrosion resistance, coefficient of thermal expansion near $6 \mu \mathrm{in} / \mathrm{in}^{\circ} \mathrm{F}$, and good fatigue characteristics.

\section{Motor Rotor}

A two pole permanent magnet synchronous motor purchased from a commercial vender was used in D1. The motor is interference fit onto the hub.

\section{Magnetic Bearings}

Each of the magnetic bearings requires a target area for the sensor and a set of laminated steel targets for the actuator. The radial magnetic bearing actuator target had to be redesigned due to the selection of a non-magnetic hub material.

Eddy current position sensors were chosen which were compatible with the hub material. The radial end sensors look directly at the hub while at the combo end the sensors look at a sensor target which is also A286 steel. Tight control of runout and surface finish is maintained on these surfaces to minimize sensor noise.
The magnetic bearing lamination assemblies are stacks of thin steel sheets with thicker end plates for assembly and axial thrust loading. Laminations of 6 mil Hiperco $50 \mathrm{HS}$ hardened to $99 \mathrm{ksi}$ were selected because they provided the best combination of magnetic properties and strength. The end plates for each lamination stack were fabricated from 4340 because Hiperco $50 \mathrm{HS}$ was not available in the required thickness. The lamination stacks are oxided and bonded into an assembly which is interference fit onto the hub.

In addition to the lamination stacks each magnetic bearing required additional components on the hub. The radial magnetic bearing utilizes a magnetic ring to provide an axial return flux path. The combo magnetic bearing has a non-magnetic spacer between the lamination stack and the sensor target ring. Both of these components are interference fit onto the hub.

\section{Touchdown Bearing Surface}

The rotor has surfaces at each end which provide a sliding interface with the stator components of the touchdown bearing. These areas have high wear and galling potential during a touchdown. A bearing steel, $440 \mathrm{C}$, hardened to $58 \mathrm{Rc}$ was chosen for these parts. This selection was based on its suitability in other tribological applications and a series of rub tests conducted at GRC with a several other candidate materials. The radial end touchdown surface only provides radial restraint. The combo end has two parts which provided radial and axial restraint.

\section{ROTOR ANALYSIS}

\section{Electromagnetic Analysis}

Full magnetic analysis was performed on the radial magnetic bearing to size the lamination stack and the return flux path ring. Rough sizing was done with a 1-D magnetic circuit analysis. Flux levels throughout the actuator and air gaps were determined and compared to saturation levels. Components were sized to operate near saturation. Finite element analysis was used to examine flux leakage areas and look for localized saturation. The inner diameter of the lamination stack and return flux path ring were reduced 0.25 " from the original pieces. The new pieces have an axial cross section area increase of $38 \%$ and a radial cross section area increase of $50 \%$ which carries flux previously carried in the hub.

\section{Rotordynamic Analysis}

Rotordynamic analysis was used to determine the bending modes of the rotor and estimate the loads during a touchdown event. The rotordynamics model is shown in Figure 5. The area above the horizontal axis is proportional to the mass distribution, while the area below is proportional to stiffness. Springs are used represent the magnetic bearing stiffness. The arrows show the unbalance locations. The first bending mode shape is superimposed on top of the model. The free-free $1^{\text {st }}$ bending mode critical speed 
is expected to be $1167-1238 \mathrm{~Hz}$ (70.0 kRPM - 74.3 kRPM) which is $17 \%-24 \%$ above the maximum operating speed $(60 \mathrm{kRPM}=1000 \mathrm{~Hz})$.

Transient analysis was done to predict the loads during a touchdown event. This is a difficult condition to model. Key variables are the mounting stiffness and damping, the bearing stiffness and damping, the net friction, and the radial gap. First, predicted transient loads are plotted vs. the key variables to determine sensitivities. After the design was finalized, the maximum transient and steady state displacements and loads during a spin down from 60,000 RPM at the two touchdown bearings were calculated. The estimate of maximum transient displacement and load was 11 mils and $700 \mathrm{lbs}$, and the estimate of maximum steady state displacement and load was 2.5 mils and $460 \mathrm{lbs}$. These estimated forces are substantially lower than the load ratings of the bearings.

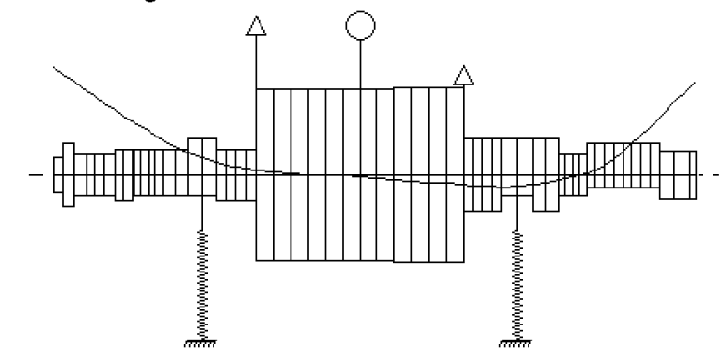

FIGURE 5 - ROTORDYNAMICS MODEL

\section{Stress Analysis}

Stress analysis was performed on the composite rim and all the metallic rotor components. Composite rim analysis verified the manufacturer's design margins. Analysis of the metallic components determined material, heat treat selection, and preload levels.

The required environmental limits and appropriate safety and knockdown factors were applied when performing the stress analysis. The analysis included the appropriate interference tolerances, speed range from 0 to the certification speed of $66 \mathrm{kRPM}$, and temperature range of $70^{\circ} \mathrm{F}$ (room) to $170^{\circ} \mathrm{F}$ (original temperature requirement). Depending on the material, margins were calculated using either von Mises or component stresses, and adequate margin was maintained to prevent separation at speed. A knockdown factor of 0.8 was applied to the nominal yield strength for materials without statistical yield strength data available. The margin of safety (MOS) is:

$$
\text { MOS }=\frac{\text { allowable stress }}{\text { FOS } \cdot \text { stress }}-1
$$

All components have positive margin of safety and maintain preload throughout the operating speed and temperature ranges and the certification conditions.

\section{Thermal Analysis}

An extremely limited thermal analysis was conducted to determine whether a rotor growth problem existed. Tests of the as-delivered hardware had shown that the rotor could axially expand during operation to a point where it made contact with the radial end touchdown bearing. The eddy current and hysteretic losses on the rotor were not well characterized, so the thermal analysis was done based on the limit temperature of the rotor. The purpose of the analysis was to find the relative growth of the rotor compared to the stator.

For this analysis, the stator temperature was assumed to be room temperature $\left(75^{\circ} \mathrm{F}\right)$, and the rotor was varied from $75 \mathrm{~F}$ to $150 \mathrm{~F}$. The expansion between the combo magnetic bearing and the combo touchdown bearing was 0.0023 ". The expansion between the combo magnetic bearing and the radial touchdown bearing was $0.0098 "$ ". Since the radial end axial expansion was greater than the clearance at the radial end touchdown bearing, the touchdown bearing system needed to be redesigned.

\section{STATOR DESIGN}

The stator redesign included changes to the touchdown bearings, the motor/generator, and the sensors. The combo end touchdown bearing system was changed to provide axial restraint in both directions. The motor/generator was switched to a different model which required redesign of the cooling jacket and mounting. New sensors for the magnetic bearing and motor generator were added.

\section{Touchdown Bearings}

The touchdown bearing system consists of two pairs of angular contact ball bearings which capture the rotor in the case of a magnetic bearing failure. The bearings are not normally engaged and have a radial and axial clearance of approximately 10 mils. In the original design each set of touchdown bearings captured the shaft radially and in one axial direction (Figure 6a). In the D1 design the shaft is captured radially and in both axial directions at the combo end, and captured only radially at the radial end.

Changing the touchdown bearing configuration

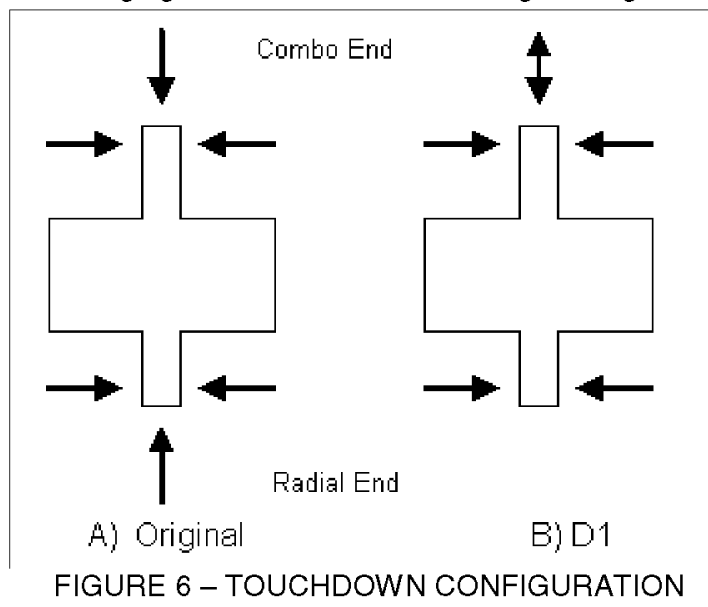


required redesign of the combo end touchdown bearing assembly. The radial end assembly could be used as is. Both ends used commercial $25 \mathrm{~mm}$ bore high speed outer race clamped angular contact bearings with silicone nitride balls. The contact surfaces were $440 \mathrm{C}$ hardened to $56-58 \mathrm{Rc}$ on the rotor and SAE52100 hardened to $62 \mathrm{Rc}$ in the bearing bore. Vacuum grease was used in the bearings. The sliding surfaces were not lubricated. The combo end bearing housing was threaded into the touchdown assembly to provide axial adjustment capability at assembly.

\section{Motor/Generator}

The D1 module has a $3 \mathrm{~kW}$ permanent magnet synchronous motor/generator. The motor voltage and number of poles were changed. The line-to-line voltage was reduced from $220 \mathrm{~V}$ to $80 \mathrm{~V}$. The new motor can be operated to 60,000 RPM using a $130 \mathrm{~V}$ DC bus. This is compatible with the International Space Station bus voltage as well as newer satellite buses. The number of poles was reduced from 4 to 2 . Consequently the synchronous drive frequency at full speed dropped from $2 \mathrm{kHz}$ to $1 \mathrm{kHz}$.

The mechanical mounting considerations were fairly straightforward. The motor requires a water cooling jacket for full power operation. The cooling jacket is also used to position the stator relative to the rotor. Axial tolerances are loose. The radial mechanical gap in the motor is $0.025 "$. The radial concentricity tolerance needs to be held tightly due to stack up error in the other stator components. The operating temperature range is $75-300^{\circ} \mathrm{F}$.

\section{Sensors}

The rotor position sensors and the tachometer sensors were replaced in the redesign. The position sensors are used in the magnetic bearing feedback control loop. Reduction in noise and runout at the sensor eliminates the need for complex filtering operations in the controller. Some of the motor/generator and magnetic bearing controllers need a tachometer signal. The tachometer was changed because the target surface used in the original design had been eliminated.

The D1 redesign will result in the second position sensor upgrade for the module. The as-delivered optical sensors had been upgraded to eddy-current sensors. Spatially related noise was greatly reduced, however electromagnetic effects were increased. Overall magnetic bearing control effort was reduced substantially. Details can be found in the work by Dever (2001). The sensor suite will be upgraded again to a new model of eddy current sensor. This model utilizes a single signal conditioning box to drive four sensor heads. Sensors are used differentially to measure shaft position. The benefits of this upgrade are that sensor to sensor crosstalk is eliminated and the commercial electronics provided a signal range that is compatible with the magnetic bearing digital controller.
Some of the control algorithms developed at GRC for motor/generator (Kenny et al 2001) or magnetic bearing control (Dever et al 2002) require rotor angular position feedback. The as-delivered hardware used an optical tachometer sensor viewing a surface on the hub. The angle was estimated based on the tachometer sensor. The D1 unit will use an eddy-current tachometer sensor viewing a target at the end of the shaft. The change was required because the original viewing area was eliminated.

\section{CONCLUSION}

The D1 flywheel module design was completed at GRC. The module combines a new rotor design, a new motor/generator, a new combo touchdown bearing, new sensors, and a redesigned radial magnetic bearing with an existing housing, magnetic bearing stators, radial end touchdown bearing, and wiring harnesses. The module redesign enables continuous operation throughout the design speed range of $0-60,000$ RPM. Energy storage capacity is similar to the original hardware, however the efficiencies of the magnetic bearing and motor/generator systems have been increased significantly. Sensor changes have also simplified the controllers.

The D1 flywheel module will be used by the Aerospace Flywheel Technology Program this year in the Attitude Control and Energy Storage Experiment. A single axis moment control and bus regulation system will be demonstrated [Kascak, 2002].

\section{REFERENCES}

T.P. Dever et al., 2001, "Evaluation and Improvement of Eddy Current Position Sensors In Magnetically Suspended Flywheel Systems," NASA/CR-2001-211137, NASA Glenn Research Center, Cleveland, $\mathrm{OH}$.

T.P. Dever et al., 2002, "Estimator Based Controller for High Speed Flywheel Magnetic Bearing System", Proceedings, IECEC 2002, Washington, D.C.

P.E. Kascak et al., 2002, "Single Axis Attitude Control and DC Bus Regulation with Two Flywheels", Proceedings, IECEC 2002, Washington, D.C.

B.H. Kenny et al., 2001, "Advanced Motor Control Test Facility for NASA GRC Flywheel Energy Storage System Technology Development Unit," NASA/ TM-2001-210986, NASA Glenn Research Center, Cleveland, $\mathrm{OH}$.

K.L. McLallin et al., 2001, "Aerospace Flywheel Technology Development for IPACS Applications," NASA/TM-2001-211093, NASA Glenn Research Center, Cleveland, $\mathrm{OH}$. 


\section{\begin{tabular}{l|l|l} 
1. AGENCY USE ONLY (Leave blank) & 2. REPORT DATE & 3. REPORT TYPE AND DATES COVERED
\end{tabular}}

Redesign of Glenn Research Center D1 Flywheel Module

Ralph H. Jansen, Robert C. Wagner, Kirsten P. Duffy, David S. Hervol,

Ronald J. Storozuk, Timothy P. Dever, Salvatore M. Anzalone, Jeffrey J. Trudell,

Kevin E. Konno, and Andrew Kenny

7. PERFORMING ORGANIZATION NAME(S) AND ADDRESS(ES)

National Aeronautics and Space Administration

John H. Glenn Research Center at Lewis Field

Cleveland, Ohio 44135-3191

5. FUNDING NUMBERS

WU-755-1A-09-00

\section{SPONSORING/MONITORING AGENCY NAME(S) AND ADDRESS(ES)}

National Aeronautics and Space Administration

Washington, DC 20546-0001
10. SPONSORING/MONITORING AGENCY REPORT NUMBER

NASA TM-2002-211788

IECEC-2002-20075

\section{SUPPLEMENTARY NOTES}

Prepared for the 37th Intersociety Energy Conversion Engineering Conference sponsored by the Institute of Electrical and Electronics Engineers, Electron Devices Society, Washington, DC, July 28-August 2, 2002. Ralph H. Jansen, Robert C. Wagner, and Kirsten P. Duffy, University of Toledo, Toledo, Ohio 43606; David S. Hervol and Ronald J. Storozuk, Analex Corporation, Brook Park, Ohio 44142; Timothy P. Dever, QSS Group, Inc., Cleveland, Ohio 44135; Salvatore M. Anzalone, Science Applications International Corporation, Cleveland, Ohio 44135; Jeffrey J. Trudell and Kevin E. Konno, NASA Glenn Research Center; Andrew Kenny, Texas A\&M University, Mechanical Engineering Department, College Station, Texas 77843-3123. Responsible person, Ralph H. Jansen, organization code 5930, 216-433-6038.

12a. DISTRIBUTION/AVAILABILITY STATEMENT

Unclassified - Unlimited

Subject Categories: 20, 33, 37, and 44

\section{2b. DISTRIBUTION CODE}

Available electronically at http://gltrs.grc.nasa.oov

This publication is available from the NASA Center for AeroSpace Information, 301-621-0390.

13. ABSTRACT (Maximum 200 words)

Glenn Research Center has completed the redesign of the D1 flywheel module. The redesign includes a new rotor with a composite rim, motor/generator, touchdown bearings, sensors, and a magnetic actuator. The purpose of the relatively low cost module upgrade is to enable it to continuously operate throughout its speed range of 0 to 60,000 RPM. The module will be used as part of a combined attitude control and bus regulation experiment.

\section{SUBJECT TERMS}

Flywheels; Reaction wheels; Counter-rotating wheels; Electric motors; Electromechanical devices

\begin{tabular}{|c|c|c|}
\hline $\begin{array}{c}\text { 17. SECURITY CLASSIFICATION } \\
\text { OF REPORT } \\
\text { Unclassified }\end{array}$ & $\begin{array}{c}\text { 18. SECURITY CLASSIFICATION } \\
\text { OF THIS PAGE } \\
\text { Unclassified }\end{array}$ & $\begin{array}{c}\text { 19. SECURITY CLASSIFICATION } \\
\text { OF ABSTRACT } \\
\text { Unclassified }\end{array}$ \\
\hline
\end{tabular}

